\title{
From Movement Control to National Recovery Plan: Malaysia's Strategy to Live with COVID-19
}

\author{
Kuok Ho Daniel Tang ${ }^{1}$ \\ ${ }^{1}$ Environmental Science Program, Division of Science and Technology, Beijing Normal University-Hong Kong \\ Baptist University United International College, 2000 Jintong Road, Tangjiawan, Zhuhai, GD 519087, China
}

\begin{abstract}
With COVID-19 vaccination gaining momentum, strict lockdowns have been perceived as no longer necessary due to their far-reaching socioeconomic impacts. This overview aims to provide insight into Malaysia's strategy in preparing to live with COVID-19 through stage-wise transition. This overview examined scholarly articles, news articles as well as official government announcements and data pertaining to the National Recovery Plan (NRP) which replaces COVID-19 lockdowns officially known as Movement Control Order (MCO) in Malaysia. NRP, which presents a stage-wise relaxation of lockdown leading ultimately to conditional reopening of all sectors and lifting of travel restrictions, adopts three major indicators for transitions of phases. The indicators are daily new COVID-19 cases, occupancy rate of intensive care units and full vaccination rate. Domestic travel initiatives have been initiated during the NRP, allowing domestic visits to certain tourist spots in the nation. Interstate travel in most parts of the nation has also been permitted without needing to show a negative COVID-19 test. On 28 October 2021, six states and three federal territories of Malaysia were already in phase 4 of NRP, which is the ultimate phase of lockdown relaxation, while all other states were in phase 3 . This has resulted in a positive outlook on the gross domestic products of Malaysia in quarter 3, 2021. This overview highlights that a different approach to COVID19 is necessary as total elimination of COVID19 is not yet in sight. It sheds light into the use of pertinent indicators or indices to capture the status of COVID-19.
\end{abstract}

Keywords: COVID-19; indicators; Malaysia; MCO; National Recovery Plan; Vaccination

\section{INTRODUCTION}

Malaysia entered into a nationwide lockdown under the Movement Control Order (MCO) on the 18 March 2020 after COVID-19 was first detected on the 25 January 2020(1)(2). MCO started with a two-week lockdown, which was subsequently extended on a fortnightly basis until the 3 May 2020, totalling altogether four phases of MCOs(1). During the periods of MCO, specific locations where large clusters existed were put under stricter control called the Enhanced MCO (EMCO) characterized by a total bar of all residents and visitors therein from leaving homes and outsiders from entering the area(3). With decreasing daily new COVID-19 cases by mid-April 2020, a relaxed version of MCO called Conditional MCO (CMCO) came into effect on the 4 May 2020 allowing most economic sectors to resume operation under strict observation of control measures typically known as standard operating procedures (SOPs) which comprised physical distancing and registration of visits. However, social and religious gathering were not allowed and interstate travel restrictions were still in place(4)(5).

CMCO was continued until 9 June 2020 after which the Recovery MCO (RMCO) took over and was typified by further relaxing of COVID-19 control measures such as the resumption of religious activities with certain restrictions, as well as reopening of entertainment, 
wellness and educational centres(6). RMCO lasted until 31 March 2021 during which MCO was selectively reinstated and CMCO was selectively extended in states with high daily new COVID-19 cases. On 31 March 2021, some states were still in CMCO. RMCO in certain states such as Sabah, Melaka, Perlis and Perak were extended from 13 to 28 April 2021(7). Besides MCO was reimposed in certain places in April and May 2021 until a nationwide MCO from 12 May to 7 June 2021 was announced(8). This reinstatement of MCO, also called MCO 3.0 saw some relaxation of the initial MCO where many non-essential sectors remained open and working from home was not as strictly imposed(8).

On 1 June 2021, the loosened variant of MCO was replaced with a total lockdown nationwide lasting till 14 June with control measures of similar stringency as the initial MCO but with certain relaxation such as a $40 \%$ of office attendance and $60 \%$ attendance for accounting services were allowed(9). On 15 June 2021, the National Recovery Plan (NRP) was announced, thus ending the era of $\mathrm{MCO}(10)$.

\section{National Recovery Plan}

Vaccination in Malaysia started on 24 February 2021 but was not able to gain momentum until June 2021(11). As of 1 July 2021, only $19.1 \%$ of the Malaysian population received at least one dose of COVID-19 vaccines but it formed a stark difference to the $2.8 \%$ recorded on 1 May 2021(11). On 27 October 2021, nearly 75\% of the population has been fully vaccinated (Figure 1)(12). The NRP was announced in the period when vaccination was taking off. It allows vaccination rate to come into the picture in the adaptive control of COVID-19 nationwide. The national recovery plan consists of four phases leading to the full opening of all economic sectors(13). The transition from one phase to another is based on three indicators, namely 1) Daily new cases of COVID-19, 2) bed utilization rate of wards in intensive care unit (ICU) and the percentage of fully vaccinated population. The three indicators reflect the transmission of COVID-19, the capacity of public healthcare system and protection of the public against COVID-19 respectively(13).

Phase one of the NRP is characterized by full movement control akin to the preceding total lockdown in response to high daily COVID-19 cases, high ICU wards occupancy and low vaccination rate(14). Transition to phase two occurs when the daily COVID-19 cases fall below 4,000 and the occupancy of ICU wards drops from a critical to a moderate level and $10 \%$ of the population are fully vaccinated. During phase 2, more economic sectors including non-essential services, gatherings of 5 fully vaccinated individuals, as well as dine-in are allowed(13). Phase 3 sees further loosening of restrictions and reopening of more sectors including education and sports, gathering rules for vaccinated individuals as well as dining. Ultimately in Phase 4, restrictions on gathering and interstate travel are lifted with social activities largely permitted(13). During the implementation of NRP, different states move into different phases of the NRP in accordance with the achievement of the three indicators. For instance, Penang entered phase 2 on 7 July 2021 and Sabah followed three days later(15). By the end of October 2021, all states were foreseen to begin their transition into phase 4 of the NRP(14). Figure 1 summarizes the timeline and features of the NRP phases. On 28 November 2021, all states, together with the Federal Territories of Kuala Lumpur, Putrajaya and Labuan were in phase 4, except the states of Sarawak and Kelantan (Figure 2). 
Kuok Ho Daniel Tang. From movement control to National Recovery Plan: Malaysia's strategy to live with COVID-19

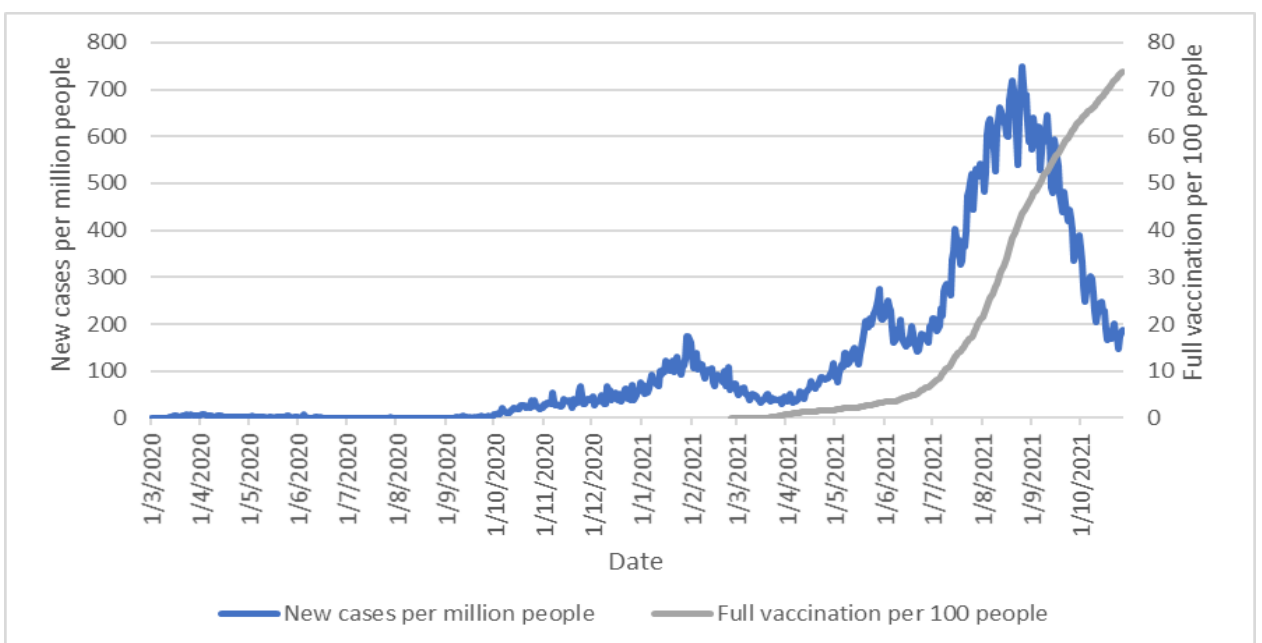

Figure 1: New COVID-19 cases and full vaccination rate in Malaysia till 27 October 2021(12)(16)

Table 1: shows the timeline and features of the four NRP phases(13)

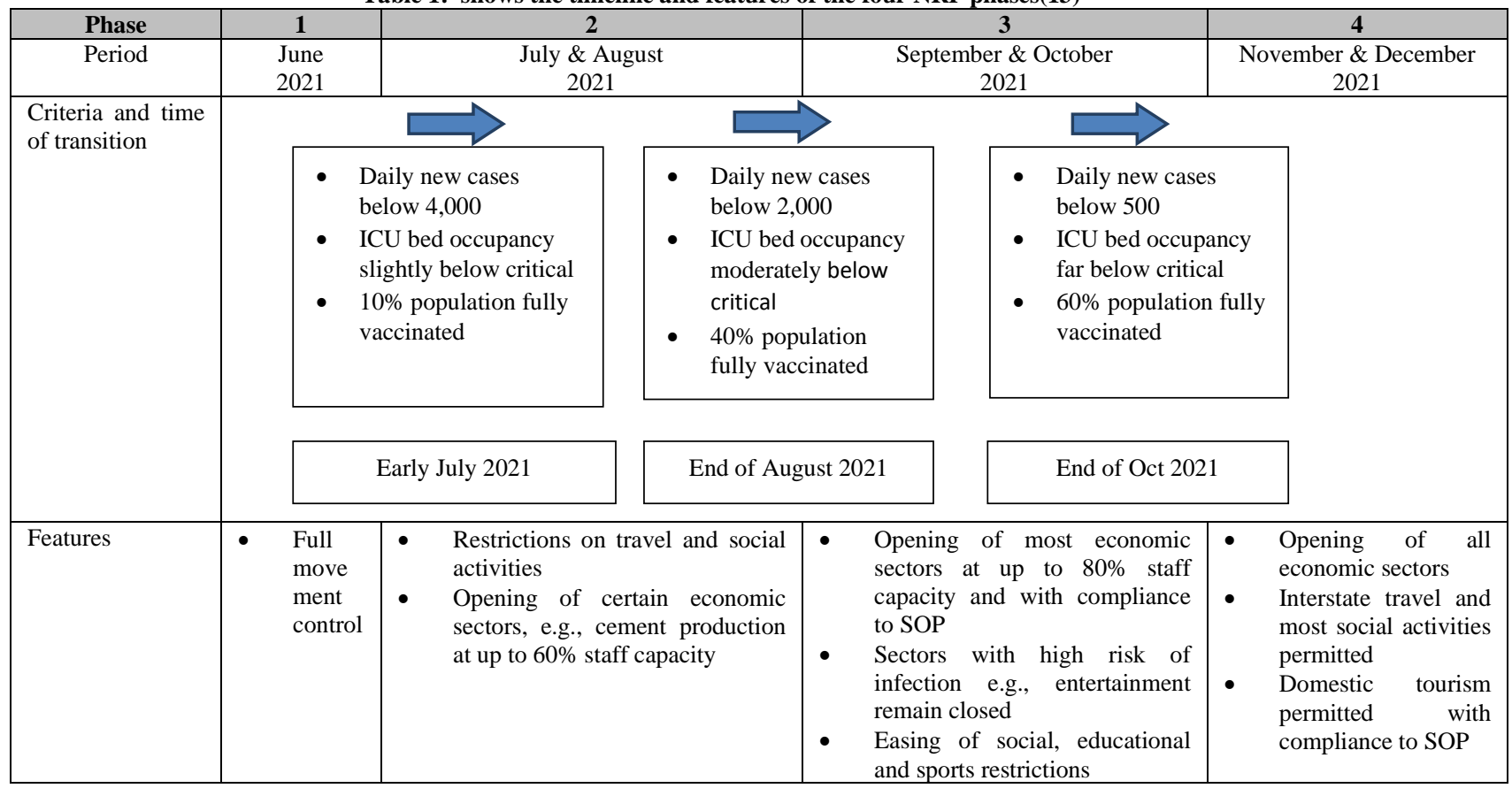

\section{Phase 1 Phase 2 Phase 3 Phase 4}
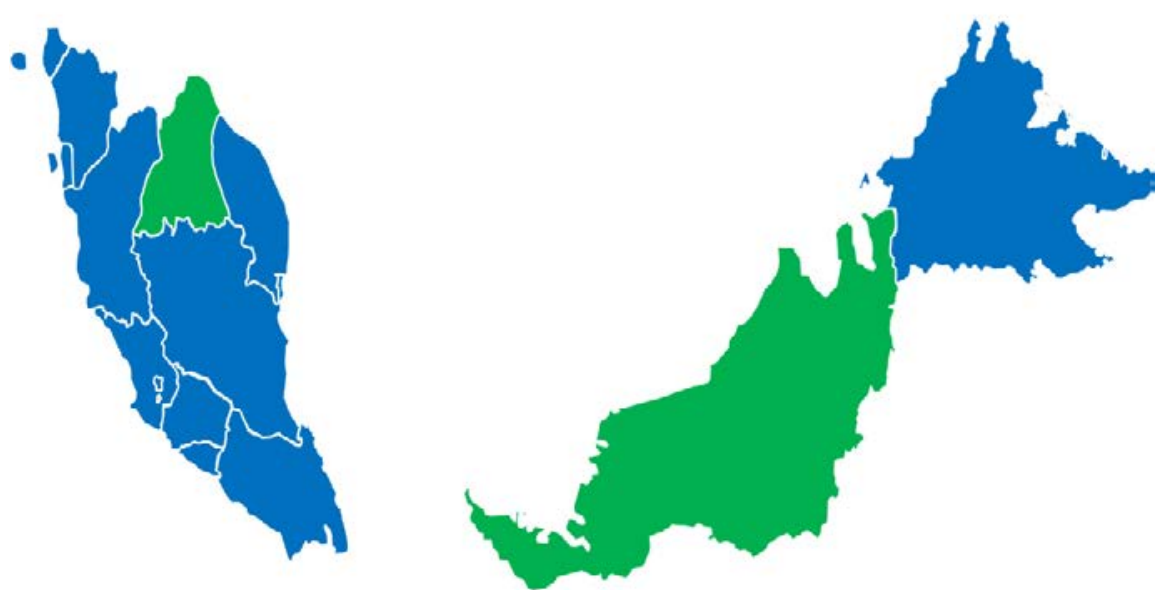

Figure 2: Phases of NRP by States in Malaysia as of 28 November 2021(17) 


\section{Implications of the National Recovery Plan}

The National Recovery Plan has seen progressive reopening of economic sectors in Malaysia and loosening of restrictions on social activities as well as interstate travel. On 11 October 2021, Malaysia lifted interstate and international travel restrictions for fully vaccinated individuals, hence requirement for travellers to obtain permission before travel(18). While international travel is still subject to the restrictions of the respective countries of destination, requirement of permits for interstate travel within Malaysia have been abolished(19). However, states in the Malaysian Borneo, namely Sabah and Sarawak, still require passengers from other states to produce negative results for RTPCR or RTK antigen tests conducted within 72 hours before departure(19). Initiatives to encourage domestic travels have begun as soon as interstate travel restrictions have been relaxed or lifted. Langkawi was opened to domestic tourism on 16 September 2021 under an experimental travel bubble initiative which garnered an encouraging 38,000 domestic arrivals(20). The travel bubble has been extended to other tourist spots such as Malacca, Genting Highlands and Tioman Island(21). Despite 149 domestic visitors were tested positive for COVID-19 during the Langkawi travel bubble, the risk was offset with rigorous screening and testing before the visitors left Langkawi(22). This did not hamper the emergence of more travel bubbles and it implies the determination of the Malaysian government to enter the era of 'living with COVID-19' with careful implementation of response strategies to contain the resulting COVID-19 transmission(23).

With the entry of Malaysia into RMCO on 10 June 2020, as well as CMCO and MCO selectively implemented in states with higher severity of COVID-19, the nation's gross domestic products (GDP) have seen progressive recovery from a contraction of $8.4 \%$ in quarter 2 of 2020 to a contraction of $3.4 \%$ in quarter 4 of
2020(24). The GDP of quarter 22021 recorded a $16.1 \%$ gain year-on-year, coinciding with RMCO and intermittent implementation of nationwide MCO variants which are relatively less stringent than the first MCO initiated at the onset of COVID-19(24). The GDP rebound pointed to the building of a recovery momentum. In June 2021, there was a silver lining in other economic indicators, for instance, the Industrial Production Index in June 2021 increased by $1.4 \%$ and the sales value of the manufacturing sector for June 2021 increased by $6.5 \%(24)$. The economic performance for quarter 3 of 2021 has not been released during the writing of this article. However, a faster recovery scenario of the Central Bank of Malaysia projected a 4\% growth of GDP in 2021 assuming that most of the nation's population has been vaccinated by the end of October 2021 (25). This projection aligns with the nation's vaccination rate that $74.8 \%$ of its population was fully vaccinated and $78.1 \%$ received at least 1 dose of vaccine as of 31 October 2021 (24).

\section{The Era of Living with COVID-19}

The move of Malaysia to progressively open up non-essential sectors within the nation, which culminates in the total opening of all sectors, is in line with the living with COVID-19 strategy promulgated by many nations, particularly Singapore. Singapore isthe pioneering nation in the Southeast Asia which advocates for living with COVID-19. On Oct 23, Singapore announced relaxed measures which include allowing fully vaccinated employees to return to workplaces from 2022, having differentiated measures for individuals exempted from vaccination, home quarantine for certain pregnant COVID-19 patients, permitting social activities for fully vaccinated seniors and allowing fully vaccinated domestic workers to enter the country(26).

Many nations in the Southeast Asia have come to realize that it impossible for COVID-19 to entirely vanish and there is a 
need to lift lockdown restrictions as vaccination drives take off. The living with COVID-19 strategy was well received by Malaysia, Indonesia and Thailand. In Thailand, plans have been made to ease lockdown restrictions and allow entry of vaccinated visitors (27). On 22 October 2021, Thailand allowed visitors of 45 countries to enter without quarantine (28). In fact, Thailand has permitted local and foreign tourists to visit Phuket as early as 1 July 2021 with conditions that they are vaccinated and tested negative for COVID19(28). This set an example for the travel bubble initiatives of Malaysia and the reopening of Bali in Indonesia to vaccinated tourists from 19 countries starting 14 October 2021(29). As the push for borders reopening heightens, it is foreseen that more countries in the Southeast Asia would follow suit.

While lockdown restrictions have the merit of controlling the transmission of COVID-19, it has hurt economies and given rise to a myriad of social problems corresponding to economic slowdown. As vaccination gains momentum, majority of the population in Malaysia and a large proportion of the Southeast Asian populations have been fully vaccinated. This has shed hope into reviving the economies through gradually easing the restrictions on non-essential sectors as well as domestic and international travels. Even though this has in certain instances, led to the rebound of COVID-19 cases, such as in Singapore, it has been argued that most of the cases are either mild or asymptomatic(16). Therefore, the path of Malaysia to join its other Southeast Asian counterparts in living with COVID-19 is already taking shape.

\section{CONCLUSION}

Many countries are no longer perceiving strict COVID-19 lockdown as feasible when their socioeconomic development is shaken to the core. With vaccination drives giving hope of reducing the severe and mild cases of COVID-19, a different approach towards COVID-19 is needed. Countries such as Singapore promulgates the notion of living with COVID-19. The UK has in fact, lifted lockdown since 19 July 2021 while the Delta variant was still ravaging. Malaysia has also started to prepare for the era of coexistence with COVID-19 through replacement of the MCO with the NRP which has seen progressive transition towards phase 4 characterized by the conditional reopening of all sectors despite that COVID-19 is still present. This is because the nation has adopted more indicators such as full vaccination coverage and criticality of ICU occupancy in addition to the daily new COVID-19 cases which was the most important indicator during the period of MCO. This overview serves to share Malaysia's experience in the transition towards coexistence with COVID-19 which is not likely to be entirely eliminated. It calls for the adoption of more indicators in determining the status of COVID-19 in addition to the three equally weighted indicators currently adopted(30). Differentiation of the indicators' weights could be considered and the development of an index could be beneficial to give an idea of the aggregated severity of COVID19(31)(32).

\section{Acknowledgement: None}

\section{Conflict of Interest: None}

\section{Source of Funding: None}

\section{REFERENCES}

1. Tang KHD. Movement control as an effective measure against Covid-19 spread in Malaysia: an overview. J Public Health (Bangkok) [Internet]. 2020; Available from: https://doi.org/10.1007/s10389-020-01316$\mathrm{w}$

2. Tang KHD. A scoping review of studies on COVID-19. Int J Sci Healthcare Res. 2020; 5(2):205-14.

3. Camoens A. Covid-19: EMCO in several localities in Selangor, KL, Terengganu and Sabah from July 1-14. The Star [Internet]. 2021 Jun 29; Available from: 
https://www.thestar.com.my/news/nation/20 21/06/29/covid-19-emco-in-severallocalities-in-selangor-kl-terengganu-andsabah-from-july-1-14

4. Bernama. Essence of conditional Movement Control Order. Bernama [Internet]. 2020 May 1; Available from: https://web.archive.org/web/202005020655 34/https://www.bernama.com/en/general/ne ws.php?id=1837487

5. Tang KHD. Controversies of The PostLockdown New Normal - It May Not be Entirely Normal [Internet]. Vol. 11, Current Research Journal of Social Sciences and Humanities. 2021. Available from: http://journalofsocialsciences.org/article/60/

6. Loo C. More sectors to be reopened under RMCO from July 1 . The Sun Daily [Internet]. 2020 Jun 26; Available from: https://web.archive.org/web/202006260814 36/https://www.thesundaily.my/covid19/more-sectors-to-be-reopened-underrmco-from-july-1-YD2630375

7. Sunil P. Malaysia extends CMCO and RMCO up til 28 April 2021 [Internet]. Human Resources Online. 2021. Available from:

https://web.archive.org/web/202005020655 34/https://www.bernama.com/en/general/ne ws.php?id=1837487

8. Rodzi N. Malaysia to reimpose $\mathrm{MCO}$ in some states: What do the Covid-19 restrictions entail. The Straits Times [Internet]. 2021 Jan 13; Available from: https://www.straitstimes.com/asia/seasia/malaysia-to-impose-mco-in-somestates-what-do-the-covid-19-restrictionsentail

9. Teoh S. Malaysia to impose total nationwide lockdown from June 1-14 as Covid-19 cases hit new record. The Straits Times [Internet]. 2021 May 29; Available from:

https://web.archive.org/web/202105290333

32/https://www.straitstimes.com/asia/seasia/full-lockdown-for-malaysia-from-june1-14

10. The Star. PM to deliver special address on National Recovery Plan at 5pm today (June 15). The Star [Internet]. 2021 Jun 15; Available from: https://www.thestar.com.my/news/nation/20 21/06/15/pm-to-deliver-special-address-onnational-recovery-plan-at-5pm-today-june15
11. Tang KHD, Chin BLF. Correlations between Control of COVID-19 Transmission and Influenza Occurrences in Malaysia. Public Health [Internet]. 2021; Available from: https://www.sciencedirect.com/science/artic le/pii/S0033350621002705

12. Mathieu E, Ritchie H, Ortiz-Ospina E, Roser M, Hasell J, Appel C, et al. A global database of COVID-19 vaccinations. Nat Hum Behav [Internet]. 2021;5(7):947-53. Available from: https://doi.org/10.1038/s41562-021-01122-8

13. National Recovery Council. National Recovery Plan: Our roadmap for Malaysia to safely exit the Covid-19 pandemic [Internet]. 2021. Available from: https://pelanpemulihannegara.gov.my/lapora n/PPN-en/index.html

14. Bernama. The National Recovery Plan: A 4phase road map out of the MCO [Internet]. 2021. Available from: https://www.bernama.com/en/infographics/i ndex.php?v=7942

15. Dermawan A. Brisk businesses for nonessential shops as Penang enters Phase 2 of NRP. New Straits Times [Internet]. 2021 Jul 7; Available from: https://www.nst.com.my/news/nation/2021/ 07/705989/brisk-businesses-non-essentialshops-penang-enters-phase-2-nrp-nsttv

16. Our World in Data. Daily new confirmed cases of COVID-19 [Internet]. 2021. Available from: https://ourworldindata.org/grapher/dailynew-confirmed-cases-of-covid-19-positiverate

17. National Recovery Council. Indicators \& current thresholds [Internet]. 2021. Available from: https://pelanpemulihannegara.gov.my/selan gor/dashboard-en.html

18. Huey Teng L. Malaysia lifts travel restrictions for fully vaccinated people. Reuters [Internet]. 2021 Oct 10; Available from: https://www.reuters.com/world/asiapacific/malaysia-lifts-travel-restrictionsfully-vaccinated-people-2021-10-10/

19. GardaWorld. Malaysia: Officials to ease restrictions on outbound international travel and interstate movement for fully vaccinated citizens from Oct. 11 [Internet]. 2021. Available from: https://www.garda.com/crisis24/newsalerts/533051/malaysia-officials-to-ease- 
restrictions-on-outbound-internationaltravel-and-interstate-movement-for-fullyvaccinated-citizens-from-oct-11-update-57

20. Nathan L. Travel bubble a success, Langkawi prepares for international visitors. FMT [Internet]. 2021 Oct 7; Available from:

https://www.freemalaysiatoday.com/categor y/nation/2021/10/07/travel-bubble-asuccess-langkawi-prepares-forinternational-visitors/

21. Soo WJ. Melaka and Tioman report steady stream of bookings after joining Malaysia's domestic travel bubble list. Malaymail [Internet]. 2021 Sep 23; Available from: https://www.malaymail.com/news/malaysia/ 2021/09/23/melaka-and-tioman-reportsteady-stream-of-bookings-after-joiningmalaysias/2007667

22. The Sun Daily. Langkawi tourism bubble: 149 Covid-19 positive cases detected Health DG. The Sun Daily [Internet]. 2021 Oct 4; Available from: https://www.thesundaily.my/local/langkawitourism-bubble-149-covid-19-positivecases-detected-health-dg-CY8427316

23. Tang KHD. A comparative overview of the primary Southeast Asian safety and health laws [Internet]. Vol. ahead-of-p, International Journal of Workplace Health Management. 2020. Available from: https://doi.org/10.1108/IJWHM-10-20190132

24. Ministry of Finance Malaysia. Malaysia's 2Q 2021 GDP grows by 16.1\%; economy expected to continue on recovery path [Internet]. 2021. Available from: https://www.mof.gov.my/en/news/pressrelease/malaysia-s-2q-2021-gdp-grows-by16-1-economy-expected-to-continue-onrecovery-path

25. Idris AN. BNM revises down Malaysia GDP forecast range to between 3\% and 4\% for 2021. The Edge Markets [Internet]. 2021 Aug 13; Available from: https://www.theedgemarkets.com/article/bn m-revises-down-malaysia-gdp-forecastrange-between-3-and-4-2021

26. Tan S-A. Living with Covid-19: New domestic, border measures announced on Oct 23. The Straits Times [Internet]. 2021
Oct 23; Available from: https://www.straitstimes.com/singapore/heal th/living-with-covid-19-new-domesticborder-measures-announced-on-oct-23

27. New Straits Times. Thailand prepares for life with Covid-19. New Straits Times [Internet]. 2021 Aug 24; Available from: https://www.nst.com.my/world/region/2021/ 08/720746/thailand-prepares-life-covid-19

28. Reuters. Thailand announces reopening rules for tourism reboot. Reuters [Internet]. 2021 Oct 22; Available from: https://www.reuters.com/world/asiapacific/thailand-announces-reopening-rulestourism-reboot-2021-10-22/

29. Gilchrist K. Indonesia's Bali is reopening to tourists - but visitors from Australia and Singapore may have to wait. CNBC [Internet]. 2021 Oct 14; Available from: https://www.cnbc.com/2021/10/15/indonesi as-bali-is-reopening-to-tourists-but-notaustralia-singapore.html

30. Tang DKH, Md Dawal SZ, Olugu EU. Actual safety performance of the Malaysian offshore oil platforms: Correlations between the leading and lagging indicators. J Safety Res [Internet]. 2018;66:9-19. Available from:

http://www.sciencedirect.com/science/articl e/pii/S0022437518300045

31. Tang KHD, Md. Dawal SZ, Olugu EU. Generating Safety Performance Scores of Offshore Oil and Gas Platforms in Malaysia. Proc One Curtin Int Postgrad Conf. 2018;(November):325-31.

32. Tang KHD, Md Dawal SZ, Olugu EU. Integrating fuzzy expert system and scoring system for safety performance evaluation of offshore oil and gas platforms in Malaysia. $\mathrm{J}$ Loss Prev Process Ind [Internet]. 2018;56:32-45. Available from: http://www.sciencedirect.com/science/articl e/pii/S0950423017305867

How to cite this article: Kuok Ho Daniel Tang. From movement control to National Recovery Plan: Malaysia's strategy to live with COVID19. International Journal of Science \& Healthcare Research. 2021; 6(4): 286-292. DOI: https://doi.org/10.52403/ijshr.20211040 